\title{
Pengaruh Aerobic Exercise Untuk Meningkatkan Fleksibilitas Hamstring Pada Calon Jamaah Umrah Kbih Al-Ikhlas Jakarta
}

\author{
Agustiyawan $^{1)}$, Nala Tsaniyah Hendrawan ${ }^{2)}$ \\ ${ }^{1,2)}$ Program Studi Fisioterapi Program Diploma Tiga , Fakultas Ilmu Kesehatan, UPN Veteran Jakarta \\ Kampus I Jl. RS Fatmawati No.1 Pondok Labu, Jakarta Selatan, Kodepos 12450 \\ Kampus II Jl. Raya Limo, Kecamatan Limo, Kota Depok, Kodepos 16515 \\ Telp. 021-7532884 \\ Email : ${ }^{1)}$ aggustiyawan@gmail.com
}

\begin{abstract}
Background: Umrah worship is usually performed by most Muslims aged 50 years or older. As you age you will experience a decrease in flexibility that can interfere with activities during the Umrah. Objective: This study aims to determine the effect of aerobic exercise to increase hamstring flexibility in prospective Umrah KBIH Al-Ikhlas Jakarta pilgrims. Method: In this study using a randomized one group pre and post test experimental method. This research was conducted at KBIH Al-Ikhlas Jakarta with a total sample of 20 people taken at random according to inclusion and exclusion criteria. The training provided in the form of aerobic exercise with brisk walking and measurement of hamstring flexibility is measured by sit and reach test. Data were processed and analyzed with SPSS 16 software applications. Results: Obtained with SPSS 16 software data that is normally distributed and homogeneous. Hypothesis test results obtained with $p=0,000$ means $p<0.05$ then there is the effect of aerobic exercise to increase the flexibility of hamstring on the pilgrims ummah pilgrims KBIH Al-Ikhlas Jakarta. Conclusion: What can be obtained from this study is that there is an effect of aerobic exercise to increase hamstring flexibility in prospective pilgrims from KBIH Al-Ikhlas Jakarta.
\end{abstract}

Keywords: Aerobic Exercise, Hamstring Flexibility, Elderly Umrah Candidates

\begin{abstract}
ABSTRAK
Latar Belakang: Ibadah umrah biasanya dilakukan oleh sebagian besar umat islam yang berusia 50 tahun lebih atau lansia. Seiring bertambahnya usia akan mengalami penurunan fleksibilitas yang dapat mengganggu kegiatan selama ibadah umrah. Tujuan: Pada penelitian ini bertujuan untuk mengetahui pengaruh aerobic exercise untuk meningkatkan fleksibilitas hamstring pada calon jamaah umrah KBIH Al-Ikhlas Jakarta. Metode: Dalam penelitian ini menggunakan metode eksperimen randomized one group pre and post test. Penelitian ini dilakukan di KBIH AlIkhlas Jakarta dengan jumlah sampel sebanyak 20 orang yang diambil secara acak sesuai dengan kriteria inklusi dan kriteria eksklusi. Latihan yang diberikan berupa aerobic exercise dengan brisk walking dan pengukuran fleksibilitas hamstring diukur dengan sit and reach test. Data diolah dan dianalisa dengan aplikasi software SPSS 16. Hasil: Diperoleh dengan software SPSS 16 data berdistribusi normal dan bersifat homogen. Hasil uji hipotesis didapatkan dengan $\mathrm{p}=0,000$ berarti $\mathrm{p}<0,05$ maka terdapat pengaruh aerobic exercise untuk meningkatkan fleksibilitas hamstring pada calon jamaah umrah KBIH Al-Ikhlas Jakarta. Kesimpulan: Yang didapat dari penelitian ini adalah terdapat pengaruh aerobic exercise untuk meningkatkan fleksibilitas hamstring pada calon jamaah umrah KBIH AlIkhlas Jakarta.
\end{abstract}

Keywords : Latihan Aerobik, Fleksibilitas Hamstring, Calon Jamaah Umrah Lansia 


\section{PENDAHULUAN}

Umrah merupakan ibadah yang hampir sama dengan ibadah umrah yang didominasi oleh aktivitas fisik sehingga para calon jamaah umrah membutuhkan kebugaran jasmani untuk kelancaran selama menjalankan ibadah umrah. Jemaah umrah Indonesia merupakan salah satu yang terbesar di dunia pada tahun 2016 mencapai 699.612 jamaah umrah. Dengan $>59,79 \%$ berjenis kelamin wanita dan dengan rentang usia terbanyak 50-64 tahun sebanyak 40,4\% [10]. Dengan rentang usia 50-64 termasuk lansia. Proses penuaan secara fisiologis munculnya perubahan sistem muskuloskeletal yang terjadi perubahan pada kolagen, menurunnya efisiensi otot dan tulang, erosi, dan kalsifikasi pada kartilago dan kapsul sendi serta mulai menurunnya kekuatan fungsional otot yang akhirnya menyebabkan menurunnya fleksibilitas pada seseorang [24]. Sehingga salah satu masalah kebugaran jasmani pada calon jamaah umrah Indonesia adalah fleksibilitas. Fleksibilitas adalah kemampuan jaringan lunak memanjang tanpa diikuti adanya keterbatasan lingkup gerak sendi (ROM) [21]. Kemampuan fleksibilitas hamstring diukur dengan sit and reach test [6]. Program latihan untuk meningkatkan fleksibilitas harus dilakukan oleh tenaga kesehatan yang memahami anatomi, fisiologi, dan biomekanik para calon jamaah umrah salah satunya adalah fisioterapi. Fisioterapi merupakan tenaga kesehatan yang memiliki tanggung jawab dalam masalah gangguan gerak dan fungsi yang dapat mengganggu aktivitas sehari-hari. Program latihan fisioterapi untuk meningkatkan fleksibilitas pada calon jamaah umrah dapat berupa latihan aerobik. Jenis aerobic exercise yang digunakan berupa brisk walking exercise untuk meningkatkan fleksibilitas pada calon jamaah umrah.

\section{TINJAUAN PUSTAKA}

\subsection{Fleksibilitas}

Fleksibilitas merupakan salah satu komponen kebugaran jasmani yang penting untuk dimiliki seseorang agar dapat menjalankan aktivitas seharihari yang dengan lancar. Fleksibilitas merupakan komponen kebugaran fisik yang berhubungan dengan kesehatan yakni kesanggupan dari sendi untuk melakukan gerakan dalam lingkup gerak sendi secara luas sesuai dengan gerakan yang mampu dilakukannya [2]. Fleksibilitas berkaitan dengan jaringan lunak yang ada dalam tubuh seseorang seperti tendon, ligamen, otot dan struktur tulang untuk memanjang tanpa diikuti adanya keterbatasan lingkup gerak sendi (ROM) [21]. Wanita cenderung memiliki fleksibilitas yang lebih baik daripada lakilaki [20]. Otot hamstring merupakan otot yang memiliki peran penting dalam setiap aktivitas manusia seperti saat berjalan, saat berlari, saat naik turun tangga dan saat duduk ke berdiri [3]. Otot hamstring juga berperan dalam setiap gerakan yang dilakukan manusia yaitu gerakan flexi lutut, extensi hip, external dan internal rotasi dan dalam fase berjalan [12]. Fleksibilitas hamstring dikatakan baik ditunjukan oleh kemampuan otot hamstring untuk berkontraksi secara konsentrik dan eksentrik secara maksimal tanpa adanya keterbatasan [19]. Apabila otot hamstring mengalami pemendekan maka akan menyebabkan cedera, menurunnya kekuatan dan keseimbangan [5].

Faktor yang dapat mempengaruhi fleksibilitas yaitu faktor secara internal maupun eksternal [16]. Faktor internal yang mempengaruhi fleksibilitas seperti genetic, struktur dan tipe sendi, jaringan otot, kekuatan otot, tendon, ligamenn, ukuran tubuh, dan suhu tubuh dan suhu otot. Faktor eksternal yang mempengaruhi fleksibilitas seperti umur, jenis kelamin, suhu lingkungan, waktu, olahraga, tingkat proses penyembuhan sendi setelah cedera, dan pakaian atau penggunaan peralatan lain pada sendi. Manfaat fleksibilitas hamstring pada calon jamaah umrah yaitu meningkatkan kebugaran fisik mengurangi cedera pada otot maupun sendi, membantu keseimbangan, koordinasi, kecepatan, dan kelincahan, efektivitas dan efisiensi tenaga atau energi yang digunakan saat melakukan kegiatankegiatan ibadah umrah, dan mampu menyelesaikan kegiatan-kegiatan dan kewajiban dalam menunaikan ibadah umrah secara optimal [18]

Pengukuran fleksibilitas hamstring dapat diukur dengan sit and reach test dengan alat yang digunakan berupa sit and reach box [6]. Dengan penilaian pada tabel 1 [4].

Tabel.1 Kategori penilaian sit and reach test

\begin{tabular}{|l|c|c|}
\hline \multicolumn{1}{|c|}{ Kategori } & Pria $(\mathrm{cm})$ & Wanita $(\mathrm{cm})$ \\
\hline High excellent & $>27$ & $17-27$ \\
\hline Excellent & $17-27$ & $21-30$ \\
\hline
\end{tabular}




\begin{tabular}{|l|c|c|}
\hline Good & $6-16$ & $11-20$ \\
\hline Mean & $0-5$ & $1-10$ \\
\hline Regular & -8 to -1 & -7 to 0 \\
\hline Poor & -20 to -9 & -15 to -8 \\
\hline High poor & $<-20$ & $<-15$ \\
\hline
\end{tabular}

Prosedur sit and reach test seperti gambar 1 [7] yaitu 1) siapkan alat-alat yang dibutuhkan dan dalam keadaan aman; 2) sampel duduk tegak di lantai, lalu kaki kira-kira selebar pinggul menempel pada sit and reach box; 3) letakan lengan yang satu diatas tangan yang satunya dan raih ke depan sejauh mungkin tanpa mengubah posisi awal; 4) lalu sampel mulai menggeser indikator jangkauan pada sit and reach box sampai jari menyentuh indikator jangkauan mendorong indikator jangkauan sejauh mungkin dan semampunya dan posisi kepala dan badan dalam posisi maju kedepan mengikuti lengan; 5) tahan selama minimal 2 detik lakukan sebanyak 3 kali; 6) pastikan bahwa selama test belakang sendi lutut rata dengan lantai; 7) lalu catat hasil testnya dari ketiga percobaan catatan hasil yang paling jauh jangkauan indikator. Seperti pada gambar 1 [7]

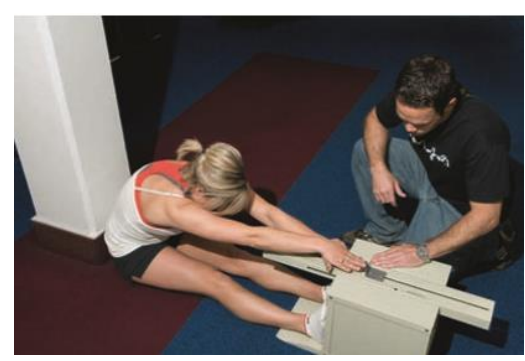

Gambar 1. Sit and reach test

\subsection{Aerobic exercise}

Salah satu cara untuk membuat tubuh tetap sehat adalah dengan olahraga yang teratur.. Salah satu jenis olahraga atau latihan adalah aerobic exercise atau latihan aerobik adalah olahraga secara sistematis dengan peningkatan beban secara bertahap dan secara terus-menerus dengan menggunakan energi yang berasal dari pembakaran dengan oksigen, dan merupakan olahraga yang membutuhkan oksigen tanpa menimbulkan rasa kelelahan [15]. Pada latihan aerobic biasanya olahraga dengan intensitas yang rendah-sedang yang dapat dilakukan dengan secara berkelanjutan dalam waktu yang cukup lama seperti jalan kaki, bersepeda maupun jogging [8]
Jenis aerobic exercise yang digunakan berupa brisk walking exercise yaitu olahraga dengan berjalan cepat walaupun tidak secepat berlari. Brisk walking merupakan bentuk moderete exercise dan merupakan yang dinamis serta ritmis yang melibatkan otot-otot besar dalam tubuh sehingga dapat memberikan manfaat dan dengan efek samping yang minimal [22]. Dengan prosedur brisk walking exercise [25] : 1) sampel melakukan pemanasan terlebih dahulu; 2) berjalan dengan langkah cepat dan atur nafas panjang secara dalam; 3) angkat sedikit kepala dan dada serta pertahankan bagian perut bawah; 4) lengan yang ditekuk pada sendi siku dengan sudut 90 derajat; 5) tutup jari-jari tangan dengan tangan santai; 6) ayunkan lengan ke depan tetap menjaga tingkat tangan agar lebih rendah dari dada dalam gerakan teratur; 7) lutut tidak seharusnya terkunci tetapi tetap santai; 8) pada saat melangkah tubuh dalam posisi tegak dan tumit yang lebih dulu menyentuh tanah diikuti oleh telapak kaki dan akhirnya ibu jari kaki yang menjadi tumpuan sebelum kaki yang lain melangkah ke depan; 9) dilakukan selama 18-20 menit. Dengan dosis $2 \mathrm{x}$ seminggu yang dilakukan selama 3 minggu, dengan jarak 1,6 Km.

\section{METODE PENELITIAN \\ 3.1 Rancangan Penelitian}

Jenis penelitian yang digunakan dalam penelitian ini adalah randomized one group pre and post test design yaitu membandingkan antara tingkat fleksibilitas hamstring sebelum dan sesudah diberikan intervensi aerobic exercise pada calon jamaah umrah KBIH Al-Ikhlas Jakarta selama 3 minggu.

\subsection{Tempat dan Waktu}

Penelitian dilakukan di Lapangan Masjid KBIH Al-Ikhlas Jakarta pada bulan Februari-Maret 2020.

\subsection{Teknik Pengambilan Sampel}

Dalam penelitian ini digunakan Teknik pengambilan sampel dengan random sampling yang mengacu dengan karakteristik tertentu yang telah ditetapkan kriteria inklusi dan eksklusi. Melakukan random sejumlah sampel dari populasi yang ada. Sampel yang terpilih menjadi subjek penelitian diberikan penjelasan mengenai penelitian ini dan sampel yang bersedia mengikuti penelitian ini diminta untuk mengisi informed consent. 


\subsection{Prosedur Intervensi}

Langkah-langkah yang diambil dalam prosedur penelitian ini dibagi menjadi beberapa prosedur seperti prosedur administrasi, prosedur pemilihan sampel dan prosedur pelaksanaan penelitian :

1. Prosedur administrasi

Pada tahap persiapan berserta administrasi penelitian yang dilakukan yaitu 1) Melakukan pengkajian keperpustakaan dari berbagai evidence based seperti buku, jurnal, internet file, dan dari berbagai topic lain yang saling berkaitan, 2) Mengurus surat-surat yang terhubungan dengan persetujuan untuk melakukan penelitian diberbagai lokasi yang ditargetkan dalam penelitian, 3) Membuat jadwal untuk pelaksaan penelitian, 4) Mempersiapkan peralatan, alat ukur dan instrument yang diperlukan selama penelitian berlangsung, 5) Mempersiapkan surat persetujuan untuk melakukan penelitian kepada subjek sampel penelitian (informed consent).

2. Prosedur pemilihan sampel

Pada tahap penentuan populasi beserta tahapan pemilihan sampel prosedur yang dilakukan adalah melakukan seleksi terhadap sampel sesuai dengan kriteria inklusi dan kriteria eksklusi yang telah ditentukan.. Dengan kriteria inklusi 1) usia 45 - 70 tahun; 2) jenis kelamin laki-laki dan perempuan; 3) tidak memiliki penyakit degenerative grade III; 4) par-Q \& You yang layak untuk melakukan latihan; 5) tekanan darah dengan sistolik $\leq 160 \mathrm{mmHg}$ dan diastolic $\leq 100 \mathrm{mmHg}$; 6) bersedia menjadi sampel penelitian dengan menandatangani atau dengan cap jempol. Kriteria Ekslusi 1) pernah melakukan latihan kebugaran dan weight training yang serupa dalam waktu 3 bulan terakhir; 2) terdapat riwayat catatan medis dan penyakit atau gangguan tulang belakang dan mengalami immobilisasi; 3) memiliki masalah cardiovaskuler dan neuromuskuler.

3. Prosedur pelaksanaan penelitian

Tahap pelakasanaan penelitian seperti: 1) Tahap pengukuran awal yang meliputi pemberian penjelasan mengenai penelitian ini, menandatangani informed consent, melakukan assessment dengan pemeriksaan vital sign, questioner dan Par-Q \& You sesuai format yang telah disediakan, melakukan pengukuran sit and reach test pre intervensi, lalu didokumentasikan hasil test dan rekapitulasi data. 2) Tahap pelatihan yang meliputi sampel melakukan pemanasan (warming up) terlebih dahulu, lalu melakukan latihan brisk walking dan setelah latihan sampel melakukan pendinginan (cooling down). 3) Tahap pengukuran akhir yang meliputi setelah sampel melakukan latihan selama 3 minggu dengan 2 kali pertemuan sampel diukur fleksibilitas hamstring dengan sit and reach test, lalu di dokumentasi hasil test dan rekapitulasi data.

\section{HASIL DAN PEMBAHASAN}

Penelitian tentang pengaruh aerobic exercise untuk meningkatkan fleksibilitas hamstring pada calon jamaah umrah KBIH AL-Ikhlas Jakarta yang telah dilakukan di Lapangan Masjid Al-Ikhlas Jakarta pada bulan Februari-Maretnte 2020 menggunakan metode penelitian eksperimental. Penelitian ini dilakukan pada 20 orang subjek yang sesuai dengan kriteria inklusi dan eksklusi tanpa kelompok kontrol. Pengukuran fleksibilitas hamstring diukur dengan sit and reach test pre dan post intervensi.

\subsection{Karakteristik Subjek Penelitian}

Untuk dapat memberikan informasi lebih lengkap dan memperkuat interpretasi hasil pengujian hipotesis, maka dipaparkan deskripsi data berupa karakteristik sampel penelitian. Deskripsi data pada tabel 2 yaitu berupa karakteristik sampel penelitian yang termasuk data numerik berupa variabel jenis kelamin, usia berat badan dan tinggi badan sebagai berikut :

\begin{tabular}{|l|c|c|c|c|c|}
\hline & Min & Max & Sum & Mean & $\begin{array}{c}\text { Std. } \\
\text { Dev }\end{array}$ \\
\hline $\begin{array}{l}\text { Jenis } \\
\text { Kela } \\
\text { min }\end{array}$ & 1 & 2 & 31 & 1.55 & .510 \\
\hline Usia & 45 & 72 & 1078 & 53.90 & 6.973 \\
\hline BB & 51 & 96 & 1333 & 66.65 & 11.156 \\
\hline TB & 153 & 171 & 3216 & 160.80 & 5.297 \\
\hline \multicolumn{7}{|c|}{ Tabel 2. Uji Deskriptif }
\end{tabular}

Tabel 2 diatas memperlihatkan karakteristik jenis kelamin, usia, berat badan dan tinggi badan dari subjek penelitian yang berjumlah 20 orang calon jamaah umrah Al-Ikhlas Jakarta. Berdasarkan karakteristik jenis kelamin dengan keterangan 1 adalah laki-laki dan 2 adalah perempuan. Dengan rerata usia sampel penelitian $1.55 \pm 0,510$ maka dengan total laki-laki 9 orang dan perempuan 11 orang. Berdasarkan karakteristik usia sampel penelitian didapatkan rerata usia $53.90 \pm 6.973$ tahun. Berdasarkan karakteristik berat badan sampel penelitian didapatkan rerata berat 
badan $66.65 \pm 11.156 \mathrm{~kg}$. Berdasarkan karakteristik tinggi badan, sampel penelitian pada tinggi badan memiliki rerata $160.80 \pm 5.927 \mathrm{~cm}$.

\subsection{Uji Normalitas}

Untuk menentukan pilihan penggunaan statistika pengujian hipotesis harus dilakukan uji persyaratan analisis yaitu uji distribusi normalitas dan uji homogenitas. Pada uji normalitas uji statistik yang digunakan berupa Shapiro-wilk test. Dengan hasil seperti pada tabel 3 sebagai berikut :

\begin{tabular}{|l|c|c|c|}
\hline \multirow{2}{*}{} & \multicolumn{3}{|c|}{ Shapiro-Wilk } \\
\cline { 2 - 4 } & Statistic & Df & Sig. \\
\hline Flexibility_Pre & .904 & 20 & .050 \\
\hline Flexibility_Post & .942 & 20 & .260 \\
\hline
\end{tabular}

Tabel 3. Hasil Uji Normalitas

Tabel 3 diatas menunjukan bahwa hasil uji normalitas dengan Shapiro-wilk test. Data berdistribusi normal jika $\mathrm{p}$ value ( $\mathrm{sig}$ ) $>0.05$. Didapatkan hasil pre intervensi 0.050 dan post intervensi 0.260 sehingga $\mathrm{p}$ value $(\mathrm{sig})>0.05$ yang berarti data berdistribusi normal.

\subsection{Uji Homogenitas}

Untuk menentukan pilihan penggunaan statistika pengujian hipotesis harus dilakukan uji persyaratan analisis yaitu uji distribusi normalitas dan uji homogenitas. Pada uji homogenitas uji statistik yang digunakan berupa Levene's test. Dengan hasil seperti pada tabel 4 sebagai berikut :

\begin{tabular}{|c|c|c|c|}
\hline & & \multicolumn{2}{|c|}{$\begin{array}{c}\text { Levene's Test for } \\
\text { Equality of } \\
\text { Variances }\end{array}$} \\
\hline & & $\mathrm{F}$ & Sig. \\
\hline $\begin{array}{l}\text { Flexibility } \\
\text { _Pre }\end{array}$ & $\begin{array}{l}\text { Equal } \\
\text { variances } \\
\text { assumed } \\
\text { Equal } \\
\text { variances not } \\
\text { assumed }\end{array}$ & .156 & .697 \\
\hline $\begin{array}{l}\text { Flexibility } \\
\text { _Post }\end{array}$ & $\begin{array}{l}\text { Equal } \\
\text { variances } \\
\text { assumed } \\
\text { Equal }\end{array}$ & .003 & .960 \\
\hline
\end{tabular}

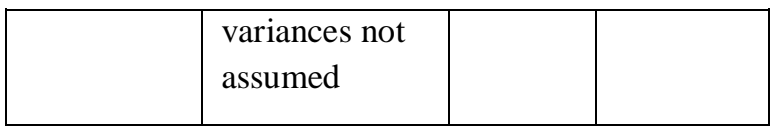

Tabel 4. Hasil Uji Homogenitas

Tabel 4 diatas menunjukan bahwa hasil uji homogenitas dengan Levene's test. Data bersifat homogen jika $\mathrm{p}$ value $(\mathrm{sig})>0.05$. Didapatkan hasil pre intervensi 0.697 dan post intervensi 0.960 sehingga $p$ value $(\mathrm{sig})>0.05$ yang berarti data bersifat homogen.

\subsection{Uji Hipotesis}

Uji hipotesis digunakan untuk mencari ada atau tidaknya pengaruh aerobic exercise untuk meningkatkan fleksibilitas hamstring sebelum dan sesudah intervensi yang diukur dengan sit and reach test. Pada uji normalitas di dapatkan data terdistribusi dengan normal (parametric) maka uji hipotesis yang digunakan adalah Paired Sampel t-test dengan hasil pada tabel 5 sebagai berikut :

\begin{tabular}{|l|r|r|r|}
\hline & \multicolumn{1}{|c|}{ Mean } & \multicolumn{1}{c|}{$\begin{array}{c}\text { Std. } \\
\text { Dev }\end{array}$} & $\begin{array}{c}\text { Sig. (2- } \\
\text { tailed) }\end{array}$ \\
\cline { 1 - 3 } Flexibility_Pre & 6.45 & 7.897 & .000 \\
\cline { 1 - 3 } Flexibility_Post & 10.55 & 7.409 & \\
\hline
\end{tabular}

Tabel 5. Hasil Uji Hipotesis

Tabel 5 menunjukan bahwa terjadinya peningkatan fleksibilitas hamstring ssudah diberikan intervensi serta menunjukan adanya perbedaan yang signifikan ( $p>0.05)$. Sehingga pada uji hipotesis ini $\mathrm{H} 1$ diterima yang berarti adanya pengaruh antara aerobic exercise untuk meningkatkan fleksibilitas hamstring pada calon jamaah umrah KBIH Al-Ikhlas Jakarta.

\subsection{Pembahasan}

Pengaruh Aerobic exercise Untuk Meningkatkan Fleksibilitas Hamstring.

Aerobic exercise memiliki manfaat yaitu dapat meningkatkan dan mempertahankan kesehatan daya jantung paru, peredaran darah, otot-otot serta pada sendi [23]. Manfaat dari brisk walking sendiri adalah manfaat seperti meningkatkan kapasitas denyut jantung dan kapasitas oksigen jaringan, merangsang kontraksi otot, peningkatan penggunaan glukosa, pemecah glikogen dan dengan efek samping yang minimal[22]. 
Aerobic exercise membuat pembuluh darah kapiler pada otot menjadi bertambah banyak, sehingga memungkinkan terjadinya proses difusi oksigen di dalam otot akan menjadi lebih mudah, sehingga memiliki kemampuan akan mengangkut dan menggunakan oksigen lebih banyak per unit massa otot sehingga dapat melakukan aktivitas secara optimal dibandingkan dengan seseorang yang tidak terlatih. Menguatkan otot jantung dapat meningkatkan kemampuan kerja jantung. Elastisitas pada pembuluh darah akan dapat meningkat sehingga jalannya darah akan semakin lancar. Lancarnya pembuluh darah juga akan memperlancar pembuangan zat sisa sehingga menjadi tidak mudah lelah dalam melakukan aktivitas dan otot rangka akan bertambah kekuatan serta fleksibilitasnya [17].

Latihan berjalan memberikan beban tersendiri yaitu berat badan dan guncangan mekanis pada otototot ekstremitas bawah yang dapat meningkatkan kekuatan otot ekstremitas bawah [1]. Berapapun jumlah langkah dan kecepatannya saat berjalan pastinya membutuhkan energi yang banyak. Berjalan merupakan latihan yang meningkatkan banyak melibatkan bagian tubuh yang melekat dalam aktivitas otot rangka serta merupakan aktivitas menahan beban yang paling sering digunakan dan dapat meningkatkan kekuatan tulang [13]. Pada saat seseorang berjalan melibatkan beberapa otot dalam tubuhnya, saat otot hamstring berkontraksi secara eksentrik saat berjalan dalam swing phase (initial swing, mid swing, terminal swing) [14].

Kontraksi eksentrik merupakan kontraksi otot yang memungkinkan otot memanjang secara alami, otot yang berkontraksi secara eksentrik merupakan otot antagonis untuk menggerakan sendi, latihan eksentrik berlangsung hanya selama 5 detik dengan total setiap gerakan eksentrik dan konsentrik adalah 10 detik [11].

Latihan eksentrik memberikan manfaat berupa meningkatkan kekuatan otot dan massa otot, menggunakan energi yang tidak terlalu banyak, kontraksi eksentrik yang maksimal mengaktifkan serat otot, setiap unit motor mendapat stimulasi lebih banyak, sebagian besar sel otot diinduksi oleh latihan eksentrik ini berfungsi sebagai sinyal untuk memulai proses adaptasi otot [3].

Kontraksi eksentrik pada otot hamstring membuat otot hamstring menjadi panjang sehingga terdapat perubahan sifat viskoelastik dari struktur tendon manusia. Peregangan menurunkan viskositas struktur tendon tetapi elastisitasnya semakin meningkat maka fleksibilitasnya juga akan meningkat [9]. Peningkatan fleksibilitas hamstring karena perubahan morfologi yang terkait dengan peningkatan sarkomer yang mengarah pada adaptasi besar pada otot hamstring dan disebabkan oleh sarkegensis saat kontraksi eksentrik, adanya peningkatan lingkup gerak sendi karena meningkatnya otot dan tendon pada hamstring, serta adanya hasil adaptasi dari spindle otot sehingga meningkatnya panjang otot yang terlibat [14]. Selama pemanjangan aktif, miofilamen diregangkan dan beberapa sarkomer akan mengalami peregangan berlebihan. Keduanya akan menjadi semakin lemah sampai miofilamen tidak lagi tumpang tindih. Tetapi ketika kontraksi eksentrik ini diulang, seiring waktu lebih banyak sarkoma akan dikonversi dari yang lebih lemah ke yang lebih kuat dan keduanya tidak akan kembali berintegrasi pada akhir setiap kontraksi. Kontraksi eksentrik dapat menyebabkan peningkatan ketegangan pasif otot sehingga menyebabkan fleksibilitas meningkat [3].

\section{KESIMPULAN}

Berdasarkan analisis penelitian yang telah dilakukan dan pembahasan dapat disimpulkan bahwa aerobic exercise pada calon jamaah umrah KBIH AlIkhlas Jakarta dengan frekuensi latihan 2x seminggu yang dilakukan selama 3 minggu memberikan pengaruh pada peningkatan fleksibilitas hamstring sehingga adanya pengaruh aerobic exercise terhadap fleksibilitas hamstring calon jamaah umrah KBIH AlIkhlas Jakarta secara signifikan.

\section{REFERENSI}

[1] Aghayari, A., Afroundeh, R., \& Saeidi Azad, P. (2016). The Effect of 6 Weeks Aerobic Training on Balance and on Flexibility in Elderly Women in Hamadan. Journal of Gerontology, 1(2), 1-9. https://doi.org/10.18869/acadpub.joge.1.2.1

[2] Arifin, Z. (2018). Pengaruh Latihan Senam Kebugaran Jasmani (SKJ) Terhadap Tingkat Kebugaran Siswa Kelas V Di Min Donomulyo Kabupaten Malang. Jurnal Of Education, 1(1), 22-29.

[3] Babu, S. K., \& Paul, A. (2018). Effectiveness of Nordic Hamstring Exercise in Improving Hamstring Muscle Flexibility, Strength and 
Endurance among Young Adults. International Journal of Health Sciences and Research, 8(3), 119-132.

[4] Castillo-Rodríguez, A., \& Chinchilla-Minguet, J. L. (2014). Cardiovascular program to improve physical fitness in those over 60 years old Pilot study. Clinical Interventions in Aging, 1269-1275. https://doi.org/10.2147/CIA.S66190

[5] Gago, I. K. S., Indra, S., \& Muliarta, I. M. (2014). Peningkatan Fleksibilitas Otot Hamstring Pada Pemberian Myofascial Release Dan Latihan Auto Stretching Sama Dengan Latihan Stretching Konvensional. Majalah Ilmiah Fisioterapi Indonesia, Volume 2, Nomor 1, 2(1), 1-11.

[6] Gil-Espinosa, F. J., Cadenas-Sanchez, C., \& Chillón, P. (2018). Physical fitness predicts the academic achievement over one-school year follow-up period in adolescents. Journal of Sports Sciences, 1-7. https://doi.org/10.1080/02640414.2018.150518 4

[7] Hoeger, W. W. K., \& Hoeger, S. A. (2012). Lifetime Physical Fitness \& Wellness (12th ed.). Cengage Learning.

[8] Irawan, M. A. (2007). Metabolisme Energi Tubuh dan Olahraga. Polton Sports Science \& Brief, 01(07), $1-9$. http://staffnew.uny.ac.id/upload/132318122/pen didikan/metabolisme+energi.pdf

[9] Kachanathu, S. J., Nuhmani, S., \& Chand, D. (2013). Efficacy of Retrowalking Versus Passive Static Stretching on Hamstring Tightness And Balance in Young Collegiate Students. Indian Journal of Applied Research, 3(9), $\quad$ 466-468. https://doi.org/10.15373/2249555x/sept2013/14 1

[10] Kementerian Agama. (2016). Statistik Jumlah Jamaah Umrah Indonesia.

[11] Leite, T. B., Costa, P. B., Leite, R. D., Novaes, J. S., Fleck, S. J., \& Simão, R. (2017). Effects of Different Number of Sets of Resistance Training on Flexibility. International Journal of Exercise Science, 10(3), 354-364. http://www.ncbi.nlm.nih.gov/pubmed/2896670 3\%0Ahttp://www.pubmedcentral.nih.gov/articl
erender.fcgi?artid=PMC5609666

[12] Megasari, P. S. K., Andayani, N. L. N., Purnawati, S., \& Wiryanthini, I. A. D. (2018). Intervensi Contract Relax Hamstring Dan Hold Relax Quadriceps Lebih Baik Dibanding Contract Relax Hamstring Dan Isotonic Exercise Quadriceps Dalam Meningkatkan Fleksibilitas Hamstring Pada Ibu-Ibu PKK Di Banjar Jambe Belodan, Desa Dauh Peken, Tabanan. Majalah Ilmiah Fisioterapi Indonesia, Volume 2, Nomor 1, 6(1), 47-50.

[13] Morris, J. N., \& Hardman, A. E. (1997). Walking to Health. Sports Medicine, 23(5), 306-332. https://doi.org/10.2165/00007256-19972305000004

[14] Muhamad, A. S., \& Yusoff, W. M. A. W. (2018). Effects Of 8 Weeks Of Eccentric Training On Hamstring Flexibility And Muscular Performance Among Healty Overweight And Obese Women. International Journal of Advances in Science Engineering and Technology, 6(2), 43-48.

[15] Palar, C. M., Wongkar, D., \& Ticoalu, S. H. R. (2015). Manfaat Latihan Olahraga Aerobik Terhadap Kebugaran Fisik Manusia. Jurnal EBiomedik (EBm), 3(1), 316-321. https://doi.org/10.35790/ebm.3.1.2015.7127

[16] Pangemanan, D. H. C., Engka, J. N. A., \& Supit, S. (2013). Gambaran Kekuatan Otot Dan Fleksibilitas Sendi Ekstremitas Atas Dan Ekstremitas Bawah Pada Siswa/I Smkn 3 Manado. Jurnal Biomedik (Jbm), 4(3), 109118. https://doi.org/10.35790/jbm.4.3.2012.1217

[17] Pribadi, A. (2015). Pelatihan Aerobik Untuk Kebugaran Paru Jantung Bagi Lansia. Jurnal Olahraga Prestasi, 11(2), 64-76.

[18] Sadjaah, E. (2006). Penguasaan Keterampilan Menari Melalui Latihan Kelenturan Gerak pada Anak Tunarungu (Pemanfaatan Waktu Luang dalam Pendidikan Luar Sekolah). Mimbar Pendidikan, 25(1), 54-61.

[19] Stephens, J., Davidson, J., DeRosa, J., Kriz, M., \& Saltzman, N. (2006). Lengthening the Hamstring Muscles Without Stretching Using "Awareness Through Movement." Physical Therapy, 86(12), 1641-1650. https://doi.org/10.2522/ptj.20040208 
Jurnal Ilmiah Fisioterapi (JIF) Volume 03 Nomor 02 Agustus 2020

[20] Suharti. (2016). Perkembangan Gerak: Kelentukan (Flexibility). Jurnal Pendidikan Olahraga Dan Kesehatan “GELORA," 3(2), 519-525.

[21] Suparwati, K. T. A., Muliarta, I. M., \& Irfan, M. (2017). Senam Tai Chi Lebih Efektif Meningkatkan Fleksibilitas Dan Keseimbangan Daripada Senam Bugar Lansia Pada Lansia Di Kota Denpasar. Sport and Fitness Journal, 5(1), 82-93.

[22] Suryati, I., Resti, D., \& Khairina, R. (2017). Kombinasi Stretching Active Dan Brisk Walking Terhadap Penurunan Tekanan Darah Klien Hipertensi Stikes Perintis Padang Email : idasuryati53@yahoo.co.id bentuk moderate exercise pada pasien hipertensi dengan menggunakan tehnik jalan cepat selama 15-30 meni. Jurnal Kesehatan Perintis, 4(2), 55-60.

[23] Tanzila, R. ayu, Chairani, L., \& Prawesti, S. anggia. (2018). Pengaruh Latihan Aerobik Terhadap Kebugaran Kardiorespirasi Pada Siswa SMP Di Palembang. Proceeding APKKM 6 FK Universitas Muhammadiyah Surabaya, 14-22.

[24] Vitalistyawati, L. P. A., Rustanti, M., Rustiana, Y., \& Suhardi, . (2019). Pengaruh Pemberian Senam Yoga Terhadap Fleksibilitas Trunk Pada Wanita Dewasa Umur 30-45 Tahun. Jurnal Kesehatan Terpadu, 3(1), 26-36. https://doi.org/10.36002/jkt.v3i1.711

[25] Wu, L. L., Wang, K. M., Liao, P. I., Kao, Y. H., \& Huang, Y. C. (2015). Effects of an 8-Week Outdoor Brisk Walking Program on Fatigue in Hi-Tech Industry Employees. Workplace Health and Safety, 63(10), 436-445. https://doi.org/10.1177/2165079915589685,

\section{Nama Penulis}

1. Agustiyawan, memperoleh Ahli Madya Fisioterapi pada tahun 2009 di Universitas Pembangunan Nasional Veteran Jakarta. Kemudian tahun 2011 memperoleh gelar Sarjana Sain Terapan Fisioterapi di STIKes Binawan Jakarta. Dan pada tahun 2015 telah menyelesaikan Program Pasca Sarjana Fisiologi Olahraga Konsentrasi Fisioterapi di Universitas Udayana. Saat ini sebagai Dosen Tetap Program Studi Fisioterapi Program Diploga Tiga Fakultas Ilmu Kesehatan Universitas Pembangunan Nasional Veteran Jakarta.

2. Nala Tsaniyah Hendrawan, mahasiswi Program Studi Fisioterapi Program Diploma Tiga, Fakultas Ilmu Kesehatan, Universitas Pembangunan Nasional Veteran Jakarta Tahun Ajaran 2017. 